\title{
IRIDOIDS OF THE BARK OF Viburnum sargenti
}

A. V. Kaminskaya, A. I. Derkach, T. A. Stepanova,

UDC 615.032 and N. F. Komissarenko

In a study of the chemical composition of the bark of Sargent cranberry bush Viburnum sargenti Koehne, together with other compounds we have detected chromatographically not less than nine substances of iridoid nature, which have been designated as compounds (1-9), the most important of them being (1), (6), and (7).

To isolate the iridoid compounds, a weighed sample of the air-dry comminuted raw material was extracted with $80 \%$ ethyl alcohol in a ratio of 1:10. The alcoholic extract obtained was evaporated to small volume and was dissolved in boiling water, and the resulting solution was filtered through a paper filter. The filtrate was cooled and was treated in a separatory funnel with chloroform $(5 \times 300 \mathrm{ml})$. The chloroform fractions were combined and evaporated to the dry state.

The chloroform fraction was deposited on a column of silica gel. The eluent consisted of mixtures of chloroform and acetone, with the concentration of the latter being gradually increased to $40 \%$. Fractions with a volume of $100 \mathrm{ml}$ were collected, their compositions being monitored by TLC in the chloroform-methanol (9:1) system. Chloroform containing $10 \%$ of acetone eluted substance (1), and chloroform with $30 \%$ of acetone substance (6), while increasing the acetone content to $40 \%$ led to the isolation of substance (7). All the substances isolated gave a blue-green coloration with the Stahl reagent [1] and a brown coloration in daylight and a yellow fluorescence in UV light with the Bacon-Edelman reagent [3].

Substance (1) $-\mathrm{C}_{33} \mathrm{H}_{48} \mathrm{O}_{18}$, colorless acicular crystals with mp $111-113^{\circ} \mathrm{C},[\alpha]_{\mathrm{D}}{ }^{20}-46^{\circ}$ (c 1.0 ; methanol), 6 , $\mathrm{C}_{29} \mathrm{H}_{42} \mathrm{O}_{16},[\alpha]_{D}{ }^{20}-65^{\circ}$ (c 3.5, chloroform) and 7, $\mathrm{C}_{27} \mathrm{H}_{40} \mathrm{O}_{15}[\alpha]_{D}^{20}-55^{\circ}$ (c 2.0, methanol).

On being boiled in the water bath with a $10 \%$ solution of hydrochloric acid in methanol for $1 \mathrm{~h}$, substances (1), (6), and (7) were converted into 7-formyl-4-methylcyclopenta[c]pyran, with $\mathrm{mp} 90-93^{\circ} \mathrm{C}\left(\mathrm{C}_{10} \mathrm{H}_{8} \mathrm{O}_{2}\right)$, which showed the presence of carbon-containing substituents in positions 4 and 7 of the iridoid nucleus.

When a 5\% ammonia solution was added to methanolic solutions of substances (1), (6), and (7), greenish-blue precipitates deposited. Alkaline hydrolysis indicated the substitution of the acetal hydroxyl at $\mathrm{C} 1$ of the iridoid nucleus by an acyl residue.

After enzymatic hydrolysis a sugar was found in the hydrolysate, which was identified by PC in various solvent systems as $D$-allose, and also isovaleric and acetic acids.

The acetylation of substances (6) and (7) led to compound (1), $\mathrm{C}_{33} \mathrm{H}_{46} \mathrm{O}_{18}, \mathrm{mp} 111-113^{\circ} \mathrm{C},[\alpha]_{D}^{20}-46$ (c 1.0 , methanol). This showed that substances (6) and (7) differed from one another by their degree of acetylation and compound (1) was the complete acetate.

The results obtained enabled substances (6) and (7) to be identified as opulus iridoids 1 and 2, and substance (1) as an acetylated opulus iridoid. All these substances have been isolated previously from the bark of European cranberry bush viburnum (V. opulus) [2].

\section{REFERENCES}

1. E. Stahl, Dünnschicht-Chromatographie: ein Laboratoriumshandbuch, 1st ed., Springer, Berlin (1962) [Russian translation, Moscow (1965); English translation, Springer/Academic Press, New York (1965)].

2. V. D. Ivanov, N. F. Komissarenko, and E. Ya. Ladygina, Khim. Prir. Soedin., 237 (1983).

3. R. B. Deff, J. S. D. Bacon, C. M. Mundie, V. C. Farmer, J. D. Bussell, and A. R. Forrester, Biochem. J., 96, 1 (1965).

Khabarovsk Pharmaceutical Instinute, Russia. Translated from Khimiya Prirodnykh Soedinenii, No. 5, pp. 684-685, September-October, 1994. Original article submitted November 15, 1993. 